\title{
Effect of Solidification Process on Magnetic Properties of Nd-Based Bulk Amorphous Forming Alloy
}

Article in Journal of Metastable and Nanocrystalline Materials · January 2004

DOI: 10.4028/www.scientific.net/JMNM.20-21.685

READS

17

6 authors, including:

\section{Wei-Hua Wang}

Chinese Academy of Sciences

462 PUBLICATIONS 13,732 CITATIONS

SEE PROFILE

\section{Y. F. Sun}

Osaka University

61 PUBLICATIONS 776 CITATIONS

SEE PROFILE
W.H. Li

Chinese Academy of Sciences

30 PUBLICATIONS 606 CITATIONS

SEE PROFILE

Yuren Wang

Chinese Academy of Sciences

61 PUBLICATIONS 724 CITATIONS

SEE PROFILE 


\title{
Effect of Solidification Process on Magnetic Properties of Nd-based Bulk Amorphous Forming Alloy
}

\author{
B. C. Wei ${ }^{1}$, W. H. Wang ${ }^{2}$, G. S. Yu' ${ }^{1}$, W. H. Li ${ }^{3}$, Y. F. Sun ${ }^{1}$ and Y. R. Wang ${ }^{1}$ \\ ${ }^{1}$ Institute of Mechanics, Chinese Academy of Science, Beijing 100080, P. R. China \\ ${ }^{2}$ Institute of Physics, Chinese Academy of Science, Beijing 100080, P. R. China \\ ${ }^{3}$ Institute of Material, Shanghai University, Shanghai 200072, P. R. China
}

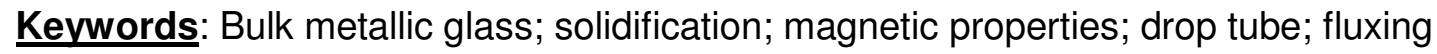

\begin{abstract}
The magnetic behavior and structure of $\mathrm{Nd}_{60} \mathrm{Al}_{10} \mathrm{Fe}_{20} \mathrm{Co}_{10}$ bulk amorphous forming alloy prepared under a wide cooling rate, from $1 \mathrm{~K} / \mathrm{s}$ to $10^{5} \mathrm{~K} / \mathrm{s}$, by means of fluxing method, drop tube, suction casting and melt-spinning were studied. The samples achieved by suction casting, melt-spinning and drop tube undergo a cooling rate larger than $30 \mathrm{~K} / \mathrm{s}$, and comprise a large fraction of amorphous phase. Samples produced by fluxing method with the cooling rate in the magnitude of $1 \mathrm{~K} / \mathrm{s}$ are fully crystallized. The room temperature hysteresis loops of the samples with high cooling rate show one ferromagnetic phase, which decomposes upon crystallization of the amorphous phase at about $750 \mathrm{~K}$. The drop tube and fluxing samples exhibit two-phase hysteresis loops at room temperature, and the hard magnetic phase is found stable upon heating to $773 \mathrm{~K}$. The crystalline hard magnetic phase in the slowly cooled sample shows comparable coercivity and Curie temperature with that of the metastable ferromagnetic phase in the amorphous alloys. These trends suggest that all phases have a similar local structure and chemical composition.
\end{abstract}

\section{Introduction}

Recently, bulk metallic glasses (BMGs) obtained in multicomponent Nd-Fe based systems have attracted great attention due to their high glass forming ability and hard magnetic properties at room temperature [1-13]. The coercivity of these alloys sensitively depends on the quenching rate. As-cast bulk samples show hard magnetic properties at room temperature, whereas the corresponding melt-spun ribbons exhibit soft magnetic behaviour [1,2,12]. A complex magnetic behavior is found in these alloys, which is related to the coexistence of Nd-rich and Fe-rich phases $[9,10,12,13]$. However, the mechanism and origin of coercivity in as-cast Nd-based alloys still remain controversial.

Previous investigations of Nd-Fe based alloys by means of melt-spinning, suction casting and injection casting normally undergo a quenching rate larger than $100 \mathrm{~K} / \mathrm{s}$. In this work, the effect of solidification process on the microstructure and magnetic properties of $\mathrm{Nd}_{60} \mathrm{Al}_{10} \mathrm{Fe}_{20} \mathrm{Co}_{10}$ alloy was systematically studied. A very slow quenching rate $(1 \sim 10 \mathrm{~K} / \mathrm{s})$ was obtained by using fluxing method, and a moderate rate $(10 \sim 100 \mathrm{~K} / \mathrm{s})$ was achieved by solidification in 52-meter drop tube.

\section{Experiments}

Ingots of $\mathrm{Nd}_{60} \mathrm{Al}_{10} \mathrm{Fe}_{20} \mathrm{Co}_{10}$ were prepared by arc-melting a mixture of the pure elements $\mathrm{Nd}$, $\mathrm{Al}, \mathrm{Fe}$ and $\mathrm{Co}$ with a purity of at least $99.9 \%$ in titanium-gettered argon atmosphere. Cylindrical specimens of $3 \mathrm{~mm}$ in diameter and $70 \mathrm{~mm}$ in length were prepared from the pre-alloyed ingots by suction casting into a copper mold. Ribbons were obtained by melt-spinning using a single copper wheel under pure argon atmosphere. The surface speed of the copper wheel was varied from 3 to 18 $\mathrm{m} / \mathrm{s}$, and the corresponding thickness of the ribbon varies from 200 to $40 \mu \mathrm{m}$. For the drop tube experiments, at the top of the $52 \mathrm{~m}$ high facility, droplets of a few millimeters in diameter are

*Corresponding author: weibc@imech.ac.cn (B. C. Wei) 
prepared from a wire by using the pendant drop technique with electron-bombardment heating. They are received onto a damping copper plate to improve cooling efficiency for a better preservation of the as-solidified microstructure. Ribbon samples with the thickness about $120 \mu \mathrm{m}$ were received by the drop tube method. For the fluxing solidification experiments, the master alloy ball with $6 \mathrm{~mm}$ in diameter was placed in $\mathrm{BN}$ crucible together with dehydrated $\mathrm{B}_{2} \mathrm{O}_{3}$. The alloy in the crucible was overheated and cooled down at controllable rate of $1 \sim 10 \mathrm{~K} / \mathrm{s}$. The center part of the sample was cut for magnetic and structural tests. The structure of the samples was characterized by X-ray diffraction (XRD) using $\mathrm{Cu} \mathrm{K} \mathrm{K}_{\alpha}$ radiation. Thermal analysis was performed with a Perkin-Elmer DSC 7 differential scanning calorimeter under argon atmosphere. The magnetic polarization as a function of the magnetic field was measured at room temperature using a vibrating sample magnetometer (VSM) with maximum applied field of $1592 \mathrm{kAm}^{-1}$. The thermomagnetic analysis (TMA) was preformed using a Faraday magnetometer at a heating and cooling rate of 0.17 $\mathrm{K} / \mathrm{s}$.

\section{Results and discussion}

Fig. 1 shows the room temperature hysteresis loops of $\mathrm{Nd}_{60} \mathrm{Al}_{10} \mathrm{Fe}_{20} \mathrm{Co}_{10}$ rod and ribbons melt-spun at different wheel speeds. The profile of hysteresis loops of $\mathrm{Nd}_{60} \mathrm{Al}_{10} \mathrm{Fe}_{20} \mathrm{Co}_{10}$ alloy changes with increasing quenching rate. The as-cast BMG exhibits coercivity $\left(H_{\mathrm{c}}\right)$ of $326 \mathrm{kAm}^{-1}$, saturation magnetization under external field of $1592 \mathrm{kAm}^{-1}\left(J_{\mathrm{s}}\right)$ of $0.16 \mathrm{~T}$ and remanent magnetization $\left(J_{r}\right)$ of $0.107 \mathrm{~T}$. For the ribbons, $H_{\mathrm{c}}$ decreases gradually from $100 \mathrm{kA} / \mathrm{m}$ to $30 \mathrm{kA} / \mathrm{m}$ with the wheel speed increases from $6 \mathrm{~m} / \mathrm{s}$ to $18 \mathrm{~m} / \mathrm{s}$. $J_{\mathrm{s}}$ and $J_{\mathrm{r}}$ slope down continuously with rising quenching rate. The $J_{\mathrm{s}}$ and $J_{\mathrm{r}}$ are $0.13 \mathrm{~T}$ and $0.05 \mathrm{~T}$ for the $6 \mathrm{~m} / \mathrm{s}$ ribbon, while $0.05 \mathrm{~T}$ and $0.02 \mathrm{~T}$ for the $18 \mathrm{~m} / \mathrm{s}$ ribbon, respectively. The magnetic properties and the tendency of coercivity to decrease with increasing the quenching rate are in accordance with other results on Nd-based metallic glass systems.

The cooling rate in the suction casting and melt-spinning process was estimated to be in the magnitude of $10^{2} \mathrm{~K} / \mathrm{s}$ and $10^{3} \sim 10^{5} \mathrm{~K} / \mathrm{s}$, respectively [14]. In order to study the effect of slow solidification process on the magnetic properties of the alloy, drop tube experiments and fluxing method were performed. Fig. 2 shows the representative room temperature hysteresis loops of $\mathrm{Nd}_{60} \mathrm{Al}_{10} \mathrm{Fe}_{20} \mathrm{Co}_{10}$ ribbon with thickness of about $120 \mu \mathrm{m}$ achieved in drop tube and of the bulk samples achieved by fluxing method under the solidification rate of about $1 \mathrm{~K} / \mathrm{s}$. An inflexion point

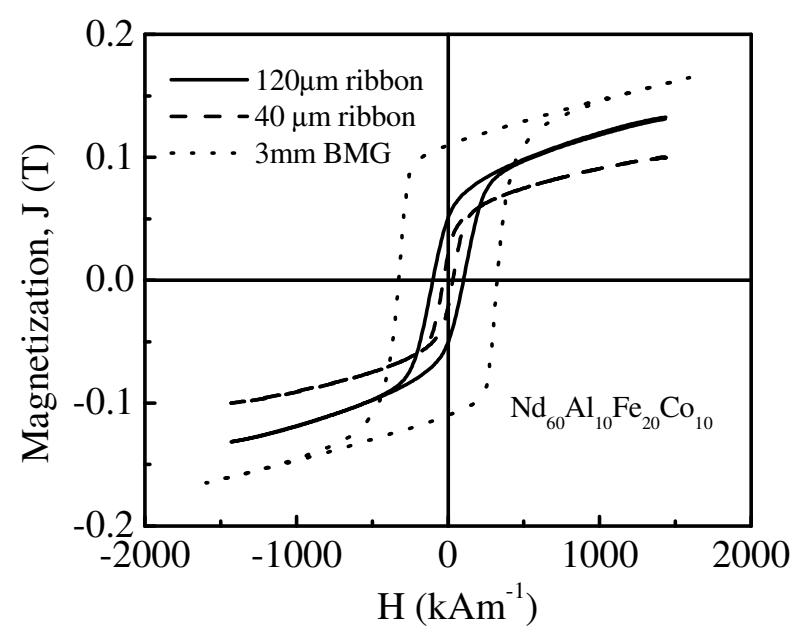

Fig. 1. Room temperature hysteresis loops of $\mathrm{Nd}_{60} \mathrm{Al}_{10} \mathrm{Fe}_{20} \mathrm{Co}_{10}$ rod and ribbons melt-spun at different wheel speed

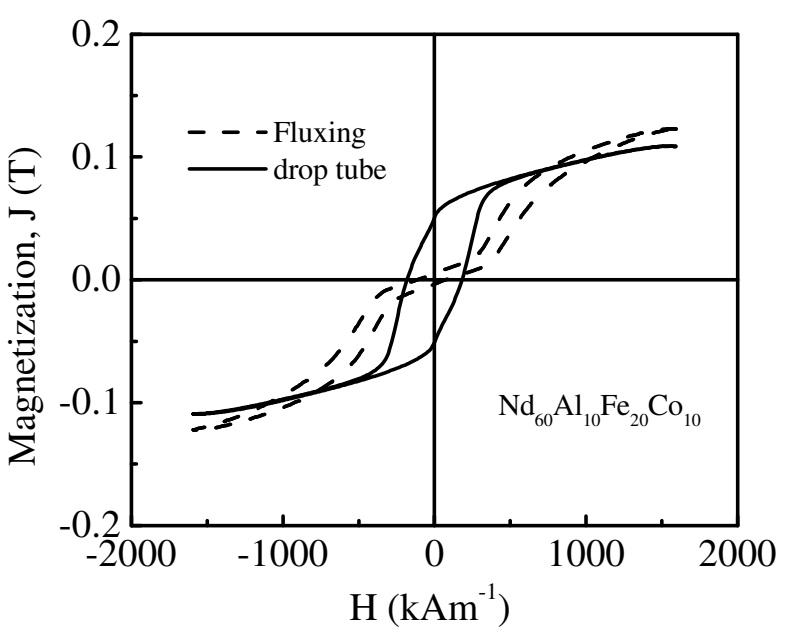

Fig. 2. Representative room temperature hysteresis loops of drop tube slice and fluxing sample 
near $H=0$ is observed in the profile of the hysteresis loops of the sample solidified in drop tube. While, an obvious two ferromagnetic phase feature is shown in the hysteresis loop of the sample solidified in fluxing. The coercivity of the hard one of the two phases is estimated to be around 350 $\mathrm{kA} / \mathrm{m}$, and is comparable with that of BMG sample shown in Fig. 1.

Fig. 3 exhibits the XRD patterns of the as-cast rod, ribbon melt spun at $6 \mathrm{~m} / \mathrm{s}$ with the thickness of about $120 \mu \mathrm{m}$, ribbon received in drop tube and of the bulk sample solidified in fluxing. It is revealed that the former three samples prepared at a relatively high cooling rate comprise a large fraction of amorphous phase, while, the bulk sample solidified slowly in the fluxing is fully crystallized.

The DSC results for the BMG, melt-spinning ribbon and drop tube ribbon are shown in Fig. 4. The sharp exothermic peak with an onset temperature $\left(T_{\mathrm{x}}\right)$ around $750 \mathrm{~K}$ in all traces corresponds to the massive crystallization of the amorphous phase. This confirms the presence of a large fraction of amorphous phase in the alloys prepared using the three routes. No exothermic peak caused by crystallization is observed in the DSC results of the sample prepared by fluxing method. This indicates that no amorphous phase exist in fluxing samples.

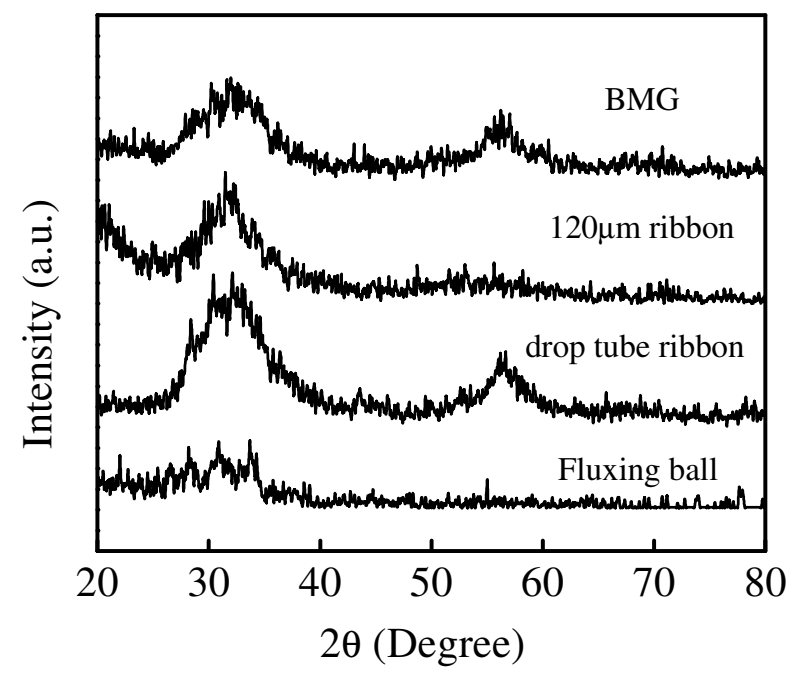

Fig. 3. XRD patterns of the samples prepared by suction casting, melt-spinning, drop tube and fluxing method

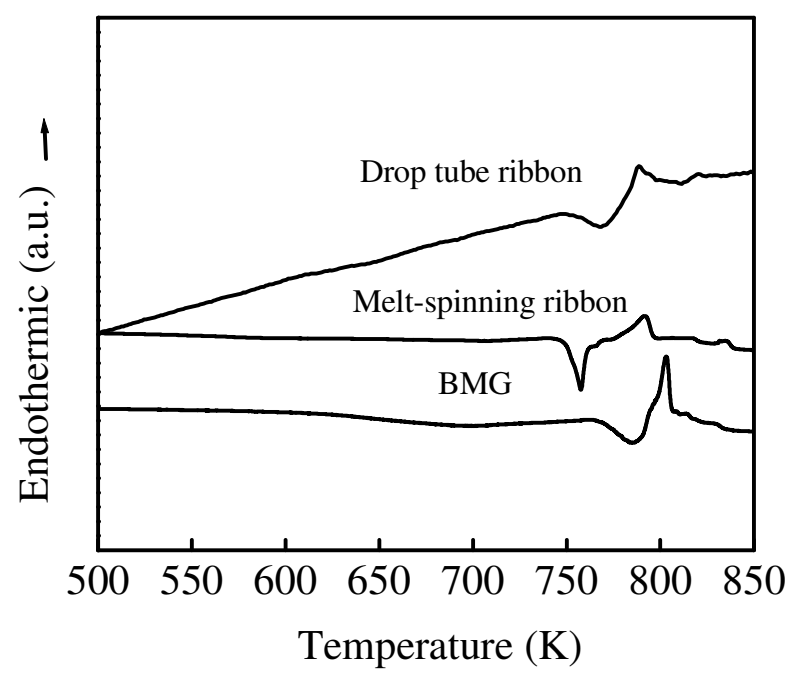

Fig. 4. DSC plots for the BMG, melt-spinning ribbon and drop tube ribbon at the heating rate of $0.17 \mathrm{~K} / \mathrm{s}$

Typical thermomagnetic analysis (TMA) plots of the samples prepared by the different routes are shown in Fig. 5. The Curie temperature $\left(T_{\mathrm{c}}\right)$ of the BMG rod is about $490 \mathrm{~K}$ (Fig. 5a). The ferromagnetic phase in the alloy decomposed upon heating up to $773 \mathrm{~K}$, as the magnetization value is very low when the alloy is cooled down again to room temperature. Our previous results confirm that the decomposition of the ferromagnetic phase in the BMG rod take places during the crystallization of amorphous phase at about $750 \mathrm{~K}$ [15]. The TMA result of the melt-spinning ribbons (not represented here) is very similar to that of the BMG rod, showing that the Curie temperature is about $495 \mathrm{~K}$ and ferromagnetic phase almost disappears upon heating to $773 \mathrm{~K}$. Fig. $5 \mathrm{~b}$ shows $T_{\mathrm{c}}$ of the drop tube sample is about $520 \mathrm{~K}$ during the heating process, while the magnetization increases below the Curie temperature when cooling down the temperature. This proves that there is still a fraction of ferromagnetic phase preserved during heating up to $773 \mathrm{~K}$ in the drop tube sample. The fluxing sample also exhibits the Curie temperature value near $515 \mathrm{~K}$ (Fig. 5c). No obvious other inflexion point in TMA plots is observed, despite two-phase hysteresis loop is pointed (Fig 2). During cooling, at temperature below the Curie temperature a stable crystalline phase orders ferromagnetically and the magnetization of the fluxing samples attains nearly the same value as that of the as-prepared one at room temperature. These results indicate that the stable 
crystalline phase dominates the magnetization of the fluxing sample, whereas, the metastable phase dominates that of the samples with higher cooling rate.

The crystalline ferromagnetic phases in the fluxing sample forms during the slow cooling process. The main crystallization occurs at about $730 \mathrm{~K}$, at which a distinct exothermic peak was observed in the cooling T-t curve. The high cooling rate in suction casting and melt-spinning method suppress the precipitation of crystalline phases from undercooled melt. The reason for the high coercivity was presumed to be the presence of a relaxed short range ordered structure that can be regarded as an ensemble of $\mathrm{Fe}$ rich $\mathrm{Nd}-\mathrm{Fe}$ clusters with large random magnetic anisotropy [2]. The crystalline hard magnetic phase in the fluxing sample show similar $T_{\mathrm{c}}$ and coercivity to that of the BMG rod. This suggests that the metastable ferromagnetic clusters in the rapidly quenched alloys possess a similar local chemical composition and structure to that of the stable phase in the slowly solidified sample. The structure and chemical composition of this stable phase are under investigation.

Despite the ribbons achieved in drop tube and the ribbon melt-spun at $6 \mathrm{~m} / \mathrm{s}$ have almost same thickness, indicating a comparable quenching rate, the drop tube samples undergo a slow cooling rate during free fall. The cooling rate of the molten droplet during the free fall period in the vacuum environment can be estimated using the following equation [16],

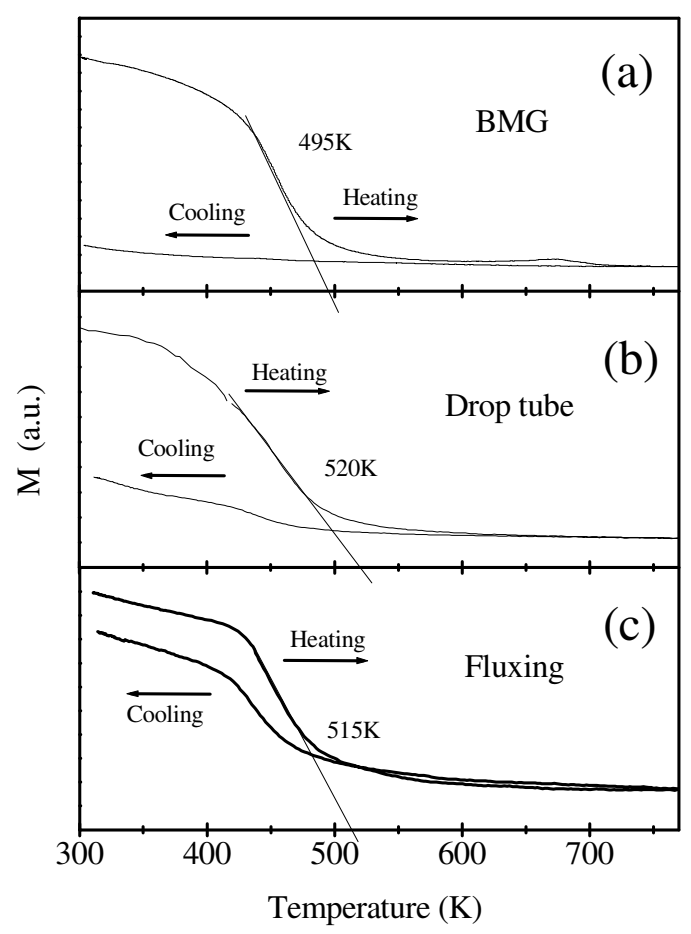

Fig. 5. Typical thermomagnetic analysis plots of the samples prepared by suction casting (a), drop tube (b), fluxing (c)

$$
\frac{d T}{d t}=-\frac{\varepsilon_{t}(T) \sigma}{C_{P}(T)} T^{4}\left[\frac{36 \pi}{m \rho^{2}(T)}\right]^{1 / 3}
$$

where $\rho$ is the liquid density, $C_{\mathrm{p}}$ the specific heat of the liquid, $m$ the mass of the droplet, $\mathcal{E}_{\mathrm{t}}$ the hemispherical emissivity, $\sigma$ the Stephan-Boltzmann constant. The calculated cooling rate of is around $30 \mathrm{~K} / \mathrm{s}$, which is lower than that in suction casting ( $3 \mathrm{~mm}$ in diameter) by nearly one magnitude. The presence of a small fraction of stable ferromagnetic phase in the drop tube ribbons confirms that the slow cooling process before quenching onto damping plated plays a important role in the formation of stable ferromagnetic phase. Furthermore, the cooling rate of tens $\mathrm{K} / \mathrm{s}$ around the melting point of this alloy (about $775 \mathrm{~K}$ calculated from Fig .4) is the critical value for the formation of stable ferromagnetic phase in this bulk amorphous forming alloy.

\section{Summary}

The solidification process has a significant effect on the magnetic properties of $\mathrm{Nd}_{60} \mathrm{Al}_{10} \mathrm{Fe}_{20} \mathrm{Co}_{10}$ bulk amorphous forming alloy. The hysteresis loops of the sample prepared by suction casting and melt-spinning show one-phase feature. The metastable hard magnetic phase decomposes upon the fully crystallization of the amorphous phase. The slow cooling period of the drop tube samples and fluxing samples produces a stable hard magnetic phase, which dominates the magnetization of the alloy prepared by fluxing method. This crystalline phase may have a similar local structure and chemical composition to the ferromagnetic clusters in the amorphous alloys 
achieved by higher cooling rate.

\section{Acknowledgments}

The authors would like to acknowledge the financial support provided by National Nature Science Foundation of China (Grant Nos. 50101012) and the Knowledge Innovation Program of Chinese Academy of Sciences.

\section{References}

[1] A. Inoue, T. Zhang, A. Takeuchi, and W. Zhang, Mater. Trans. JIM, Vol. 37 (1996), p. 636.

[2] A. Inoue, A. Takeuchi, and T. Zhang, Metall. and Mater. Trans. Vol. 29A (1998), p. 1779.

[3] Y. Li, S. C. Ng, Z. P. Lu, Y. P. Feng, and K. Lu, Phil. Mag. Lett. Vol. 78 (1998), p. 213.

[4] L. Q. Xing, J. Eckert, W. Löser, S. Roth, and L. Schultz, J. Appl. Phys. Vol. 88 (2000), p. 3565 .

[5] H. Chiriac, N. Lupu, J. Non-Cryst. Solids, Vol. 287 (2001), p. 135.

[6] B. C. Wei, W. H. Wang, M. X. Pan, B. S. Han, Z. R. Zhang, and W. R. Hu, Phys. Rev. B, Vol. 64 (2001), 012406.

[7] M. X. Pan, B. C. Wei, L. Xia and W. H. Wang et al. Intermetallics, Vol. 10 (2002), p. 1215

[8] B. C. Wei, W. Löser, L. Xia, S. Roth, M. X. Pan, W. H. Wang and J. Eckert, Acta Mater. Vol. 50 (2002), p. 4357

[9] G. Kumar, J. Eckert, S. Roth, W. Löser, S. Ram, L. Schultz, J. Appl. Phys. Vol. 91 (2002), p. 3764

[10] Z. G. Sun, W. Löser, J. Eckert, K,-H. Müller, L. Schultz, Appl. Phys. Lett. Vol. 80 (2002), p. 772

[11] R. J. Ortega-Hertogs, A. Inoue, and K. V. Rao, Scripta Mater. Vol. 44 (2001), p. 1333.

[12] L. Xia, B. C. Wei, Z. Zhang, M. X. Pan et al. J. Phys. D: Appl. Phys. Vol. 36 (2003), p. 1

[13] Z. Zhang, L. Xia, R. J. Wang, and B. C. Wei et al. Appl. Phys. Lett. Vol. 81 (2002), p. 4371

[14] A. Takeuchi, A. Inoue, Mater. Sci. Eng. Vol. A304-306 (2001), p. 446

[15] B. C. Wei, W. H. Wang, L. Xia, Z. Zhang, D. Q. Zhao, and M. X. Pan, Mater. Sci. Eng. Vol. A334 (2002), p. 307

[16] S. Tournier, B. Vinet, A. Pasturel, I. Ansara and P. J. Desre, Phys. Rev. B Vol. 57 (1998), p. 3340 